\title{
Experimental study of casing wear under impact-sliding conditions
}

\author{
Chu Shengli, Zhang Laibin*, Fan Jianchun, Zheng Wenpei and Yu Huiyuan
}

School of Mechanical and Electronic Engineering, China University of Petroleum, Beijing 102249, China

\begin{abstract}
Theoretical analysis and field monitoring show that lateral vibration has very important effect on casing wear in deep \& ultra-deep well drilling. The wear mechanism of casing under impact-sliding work conditions has been investigated and many experiments have been completed with a newly developed full-scale casing wear test machine. Test results present that adhesion wear, contact fatigue, and grinding abrasion are the main wear mechanisms under impact-sliding test conditions. The friction coefficient and linear wear rate of the casing rise obviously with an increase in impact load. And the larger the impact load, the rougher the worn surface of the casing. The linear wear rate decreased slightly but the average friction coefficient increased slightly with an increase in impact frequency under an impact load of 2,500 $\mathrm{N}$. Both the linear wear rate of the casing and the average friction coefficient increased substantially with an increase in impact frequency under an impact load of 4,000 N. Under lower impact load conditions, grinding abrasion and contact fatigue are the main mechanisms of casing wear; under higher impact load conditions, adhesion wear and contact fatigue are the main mechanisms of casing wear.
\end{abstract}

Key words: Casing wear, impact-sliding conditions, experimental study, wear mechanism

\section{Introduction}

In the western oilfields of China, casing wear occurs frequently in deep or ultra-deep well drilling, which can lead to severe drilling accidents. However, casing wear has already been one of the pivotal factors leading to high costs in drilling engineering (Zheng and Wang, 2003).

Research indicates that the rotation of drilling-pipes and the lateral load between contact-surfaces are key factors of casing wear. In a vertical well, severe casing wear usually occurs on the sections with large dog-leg severity or near the mouth of a well where the maximum pull force existed in the drilling pipe (Bradley and Fontenot, 1975; Best, 1986; Bol, 1986).

Different from the wear occurring in a common vertical well, the severe casing wear in the deep and ultra-deep well drilling in the western oilfields of China, usually takes place in deep sections of wells where the lateral pressure on the casing inner surface seems to be lower, sometimes even the dog-leg severity was very small. Field monitoring has found a lot of fatigue casing debris in drilling fluid. Current casing wear theory based on common vertical well drilling engineering cannot explain this phenomenon (Zhang et al, 2002).

Some researchers consider that the lateral vibration of the drilling-pipe in the deep section of a well can cause a great dynamic load on the casing which may lead to severe casing wear (Mitchell and Allen, 1985; Fan et al, 2004; Gao

*Corresponding author. email: Zhanglb@cup.edu.cn Received September 27, 2008 and Gao, 1996). But in the absence of an impact-sliding tester for casing wear, this hypothesis has not been confirmed by experiments. Using the newly developed DCWT casing wear tester, a series of experiments under impact-sliding work conditions have been performed for exploring the wear mechanisms.

\section{Casing-wear test facility and procedure}

A DCWT-1000 casing-wear test facility used is a new type of full-scale impact-sliding test machine (Chu et al, 2007), and its schematic diagram is shown in Fig. 1. The tool-joint sample was mounted on a rotating shaft, which was linked to the reciprocating stage by two gears. The rotating shaft drove the tool-joint sample to rotate and the reciprocating stage drove the rotating shaft to move up and down. Thus, the machine built could be used to carry out impact-sliding wear tests. The casing was fixed on a floating landing stage

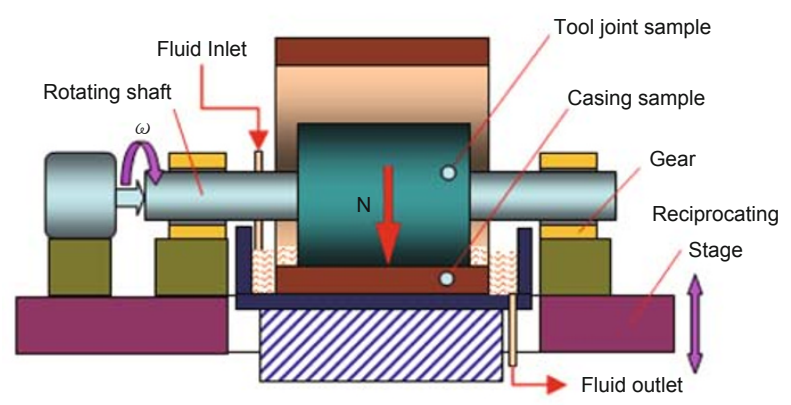

Fig. 1 Schematic diagram of casing-wear tester 
with a force sensor that could measure real-time contact force between the casing and the tool joint. Wall thickness loss and driving torque were measured on-line as well (Chu, 2006).

In the western oilfields in China, the conventional drill pipe rotary speed is $60-120 \mathrm{rpm}$ (revolutions per minute). The literature analyses (Han et al, 2004; Chu et al, 2008) indicated that the lateral vibration frequency of the multi drill pipe was 23-237 times per minute, and then the impact load (or impact force) applied to the drill pipe near the neutral point was $4,617 \mathrm{~N}$. Based on the above analyses, the main test parameters are listed in Table 1. Water-based drilling fluid was used as lubrication and its formulation is listed in Table 2. All samples were cut from real products, and their physical properties are shown in Table 3.

Table 1 Main conditions of impact-sliding wear test

\begin{tabular}{cccc}
\hline $\begin{array}{c}\text { Rotary speed } \\
\text { rpm }\end{array}$ & $\begin{array}{c}\text { Impact load } \\
\mathrm{N}\end{array}$ & $\begin{array}{c}\text { Impact frequency } \\
\mathrm{Hz}\end{array}$ & $\begin{array}{c}\text { Test time } \\
\mathrm{h}\end{array}$ \\
\hline $120-180$ & $2500-6000$ & $1-4$ & 8 \\
\hline
\end{tabular}

Table 2 Drilling fluid formulation

\begin{tabular}{ccccccc}
\hline $\begin{array}{c}\text { Bentonite } \\
\%\end{array}$ & $\begin{array}{c}\mathrm{Na}_{2} \mathrm{CO}_{3} \\
\%\end{array}$ & $\begin{array}{c}\mathrm{NaOH} \\
\%\end{array}$ & $\begin{array}{c}\mathrm{NAT20} \\
\%\end{array}$ & $\begin{array}{c}\text { IND30 } \\
\%\end{array}$ & $\begin{array}{c}\mathrm{NFA25} \\
\%\end{array}$ & $\begin{array}{c}\text { Density } \\
\mathrm{g} / \mathrm{cm}^{3}\end{array}$ \\
\hline 2 & 0.2 & 0.2 & 1.5 & 0.2 & 1.5 & 1.03 \\
\hline
\end{tabular}

Table 3 Physical properties and sizes of samples used

\begin{tabular}{ccccc}
\hline Sample & Material & $\begin{array}{c}\text { Hardness } \\
(\text { HRC })\end{array}$ & $\begin{array}{c}\text { Diameter } \\
\mathrm{mm}\end{array}$ & $\begin{array}{c}\text { Width } \\
\mathrm{mm}\end{array}$ \\
\hline Casing & TP110 & 47 & 244.5 & 100 \\
Tool-joint & $\mathrm{S} 135$ & 33 & 168 & 80 \\
\hline
\end{tabular}

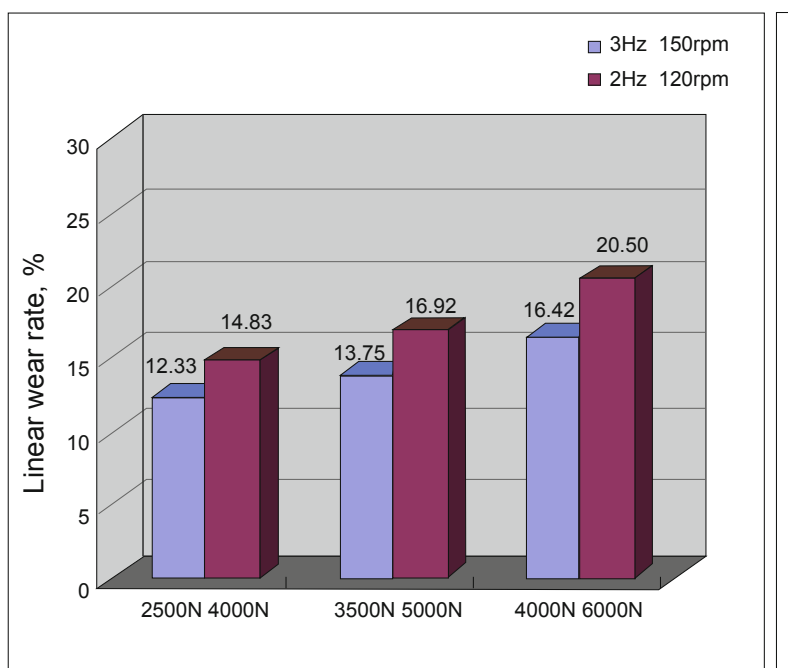

\section{Experimental results and discussion}

With the new type of impact-sliding wear tester, a series of casing wear tests were conducted under sliding-impact work conditions. The influences of impact parameters on casing wear were studied in detail.

\subsection{Influence of impact load on casing wear}

In this paper, the thickness loss of the casing wall (wear depth), linear wear rate, and friction coefficient were introduced to evaluate casing wear. The linear wear rate was defined as the wear depth divided by the initial thickness of the casing wall. Fig. 2 shows test results of linear wear rate and average friction coefficient under two different impact conditions. Fig. 3 shows the variation in thickness loss of the casing wall with wear time under different impact loads and frequency conditions. Eight hour wear test results showed that the linear wear rate, friction coefficient, and wall thickness loss of casings increased significantly as the impact load increased. The three-dimensional topography of worn surface of casings after wear test were measured with casing surface topography test equipment (Chen et al, 2007) and shown in Fig. 4. For comparison, the surface of the casing before wear test was also shown in Fig. 4. It is clearly shown that as the impact load increased, the worn surface of the casing became more uneven, more noticeably convex peaks and concave cavities were visible on the worn surface of casings, and more rough peaks were detected. The larger the impact load, the rougher the worn surface of casing.

\subsection{Influence of impact frequency on casing wear}

Eight hour wear test results (Fig. 5) showed that the linear wear rate decreased slightly but the average friction coefficient increased slightly with an increase in impact frequency under relative low impact load $(2,500 \mathrm{~N})$. However, both the linear wear rate of the casing and average friction coefficient increased substantially with an increase in impact frequency under relative high impact load $(4,000 \mathrm{~N})$.

Fig. 2 Linear wear rate of casings and friction coefficient under different impact load conditions 


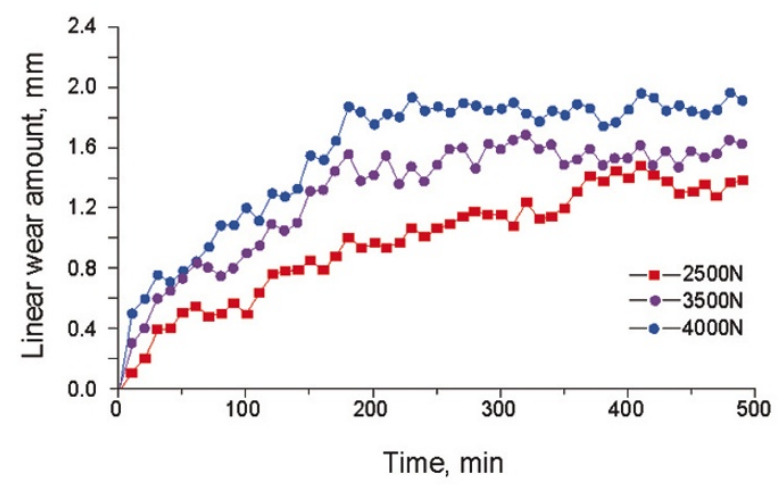

(a) $3 \mathrm{~Hz}, 150 \mathrm{rpm}$

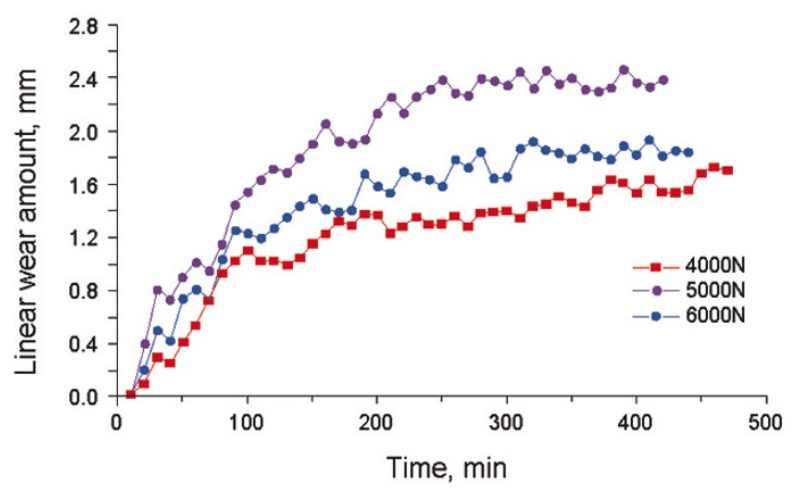

(b) $2 \mathrm{~Hz}, 120 \mathrm{rpm}$

Fig. 3 Variation in dynamic thickness loss of casing wall under different impact load conditions

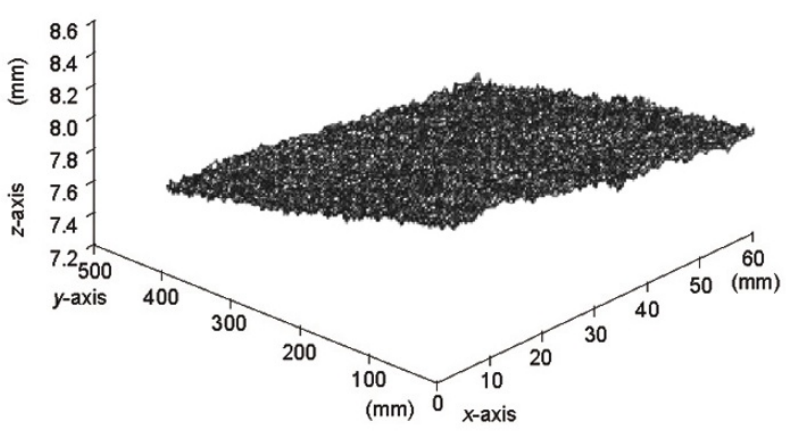

(a) Before wear test

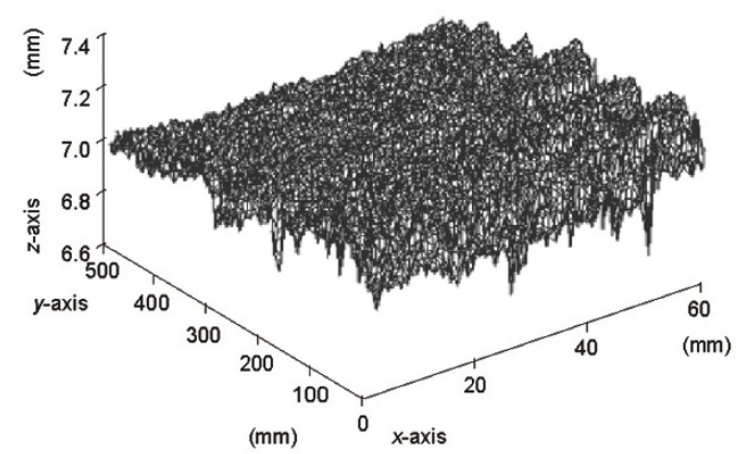

(c) Casing surface worn under an impact load of $3500 \mathrm{~N}$

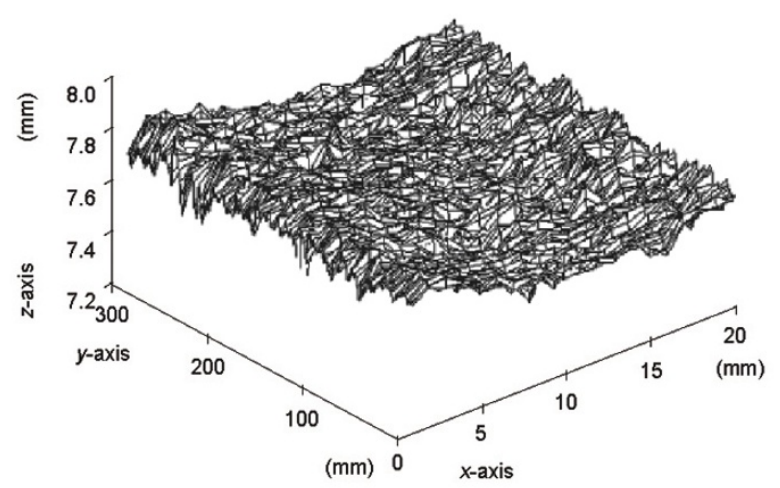

(b) Casing surface worn under an impact load of $2500 \mathrm{~N}$

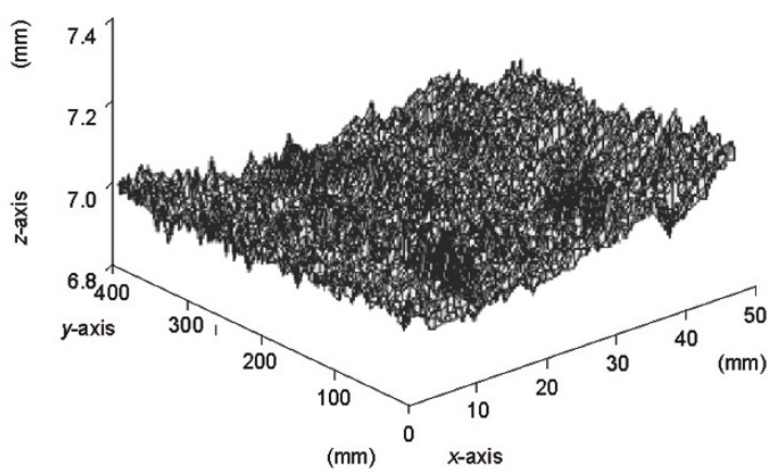

(d) Casing surface worn under an impact load of $4000 \mathrm{~N}$

Fig. 4 3-D surface topography of casings before and after wear tests

The dynamic casing wear under different impact frequency and impact load values was presented in Fig. 6 . The eight hour test results showed that when impact frequency was relative low $(2 \mathrm{~Hz})$ the casing wear increased more rapidly at the early stage of wear tests, but when the impact frequency was relative high $(3 \mathrm{~Hz})$ the casing wear increased slowly at the early stage of wear tests and quickly at the later stage. A reason for this result is that during an impact cycle, relative longer contact time between two samples can cause more casing wear under relative low load $(2,500 \mathrm{~N})$ and impact frequency. However, under high impact load $(4,000$ $\mathrm{N}$ ) and frequency (more than $2 \mathrm{~Hz}$ ) fatigue micro-cracks form more easily on the surfaces of samples, and the fatigue wear results in more casing wear (shown in the Fig. 6(b)). Fig. 7 showed that the casing surface worn under higher impact frequency was rougher than that worn under lower impact frequency.

Typical optical and SEM images of casing surfaces worn under different test conditions are shown in Fig. 8. Noticeable plastic flow and plastic accumulation were observed on the optical image of the casing wear surface when the wear test was performed at an impact frequency of $2 \mathrm{~Hz}$ and an impact load of 2,500 N (shown in the left-hand side of Fig. 8(a)). Many fatigue flakes were observed clearly in its SEM image. 

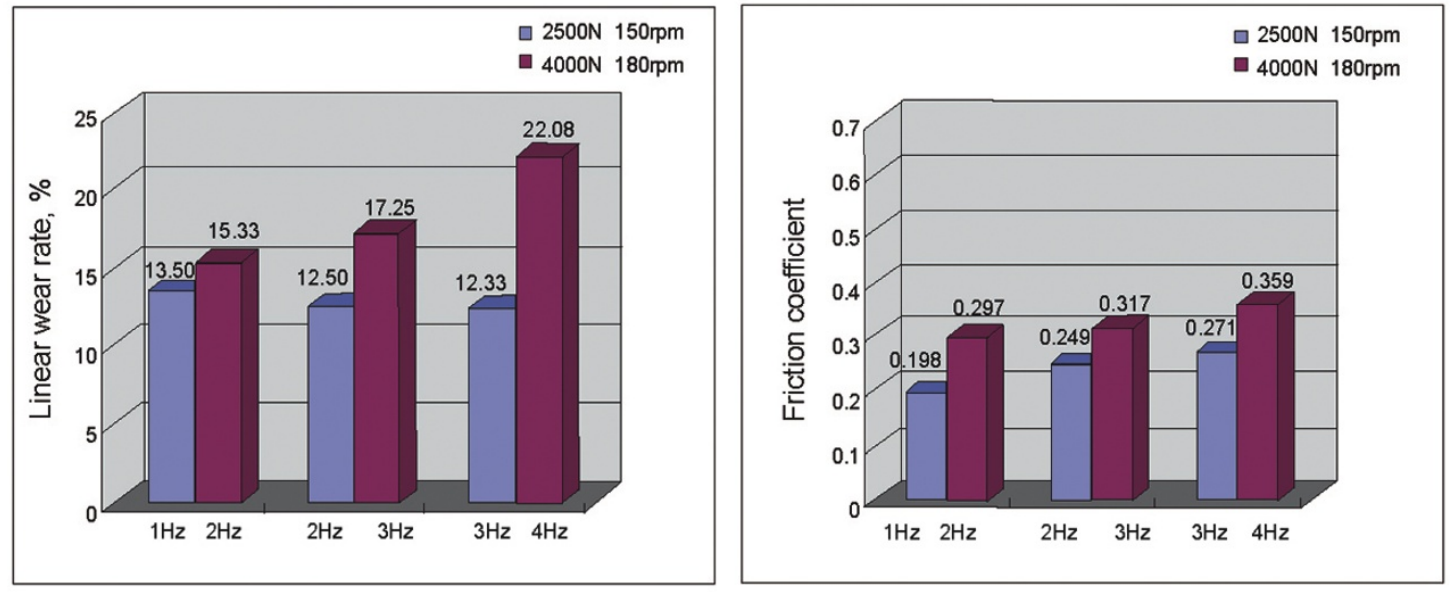

Fig 5 Linear wear rate of casings and friction coefficient under different impact frequency conditions

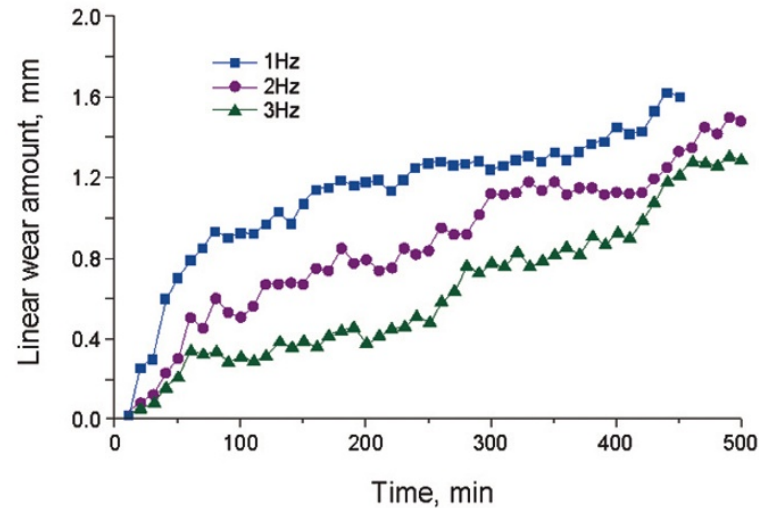

(a) $2500 \mathrm{~N}, 150 \mathrm{rpm}$

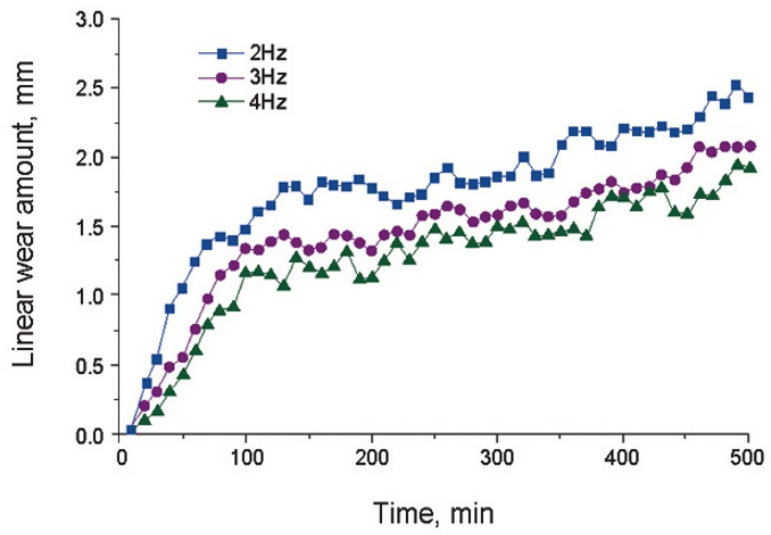

(b) $4000 \mathrm{~N}, 180 \mathrm{rpm}$

Fig. 6 Variation in dynamic linear wear rate under different impact load conditions

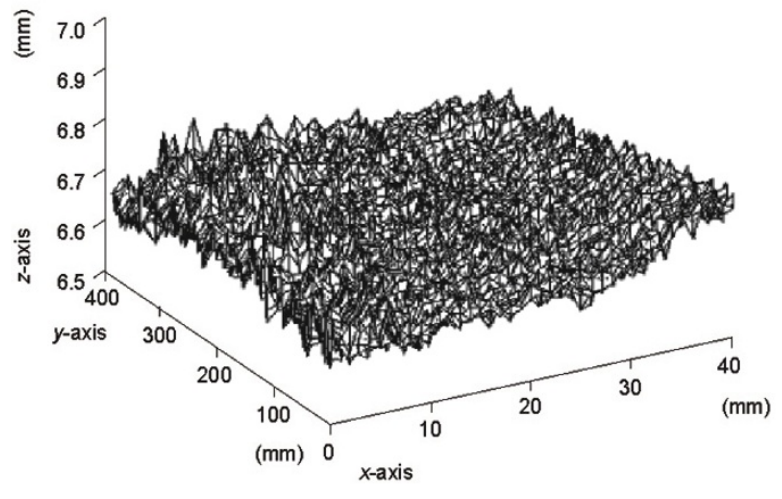

(a) $2 \mathrm{~Hz}$

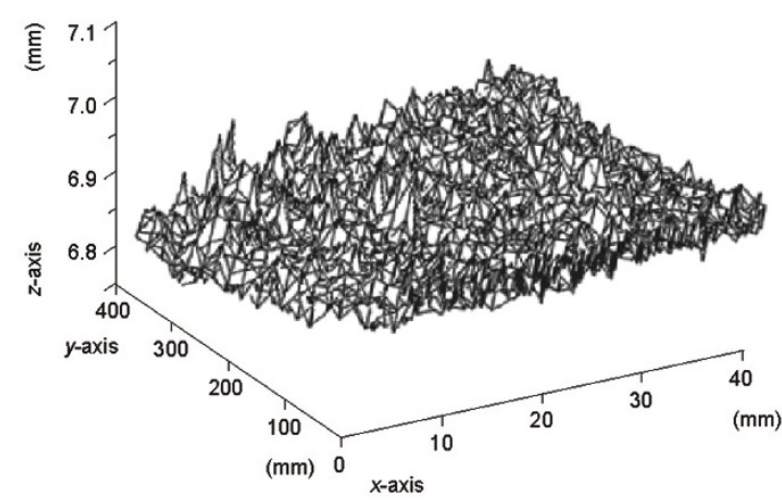

(b) $3 \mathrm{~Hz}$

Fig. 73-D wear surface topography of casings under an impact load of $4000 \mathrm{~N}$

Fig. 8(b) showed that serious ploughed furrows and fatigue pits, which connected with fatigue cracks, were formed on the worn surface of casings (shown on the optical image of Fig. 8(b)), and large fatigue cavities linked with fatigue cracks occurred on the surface of casings worn against the tool joint at an impact frequency of $3 \mathrm{~Hz}$. Adhesive wear and large fatigue peelings, and a number of spherical fatigue-wear particles were visible on the SEM image of Fig. 8(b).

Obvious fatigue wear and adhesion appeared on the casing surface under an impact load of $4,000 \mathrm{~N}$. It can be seen from Fig. 8(c), the generated fatigue cracks propagated continuously and were accompanied by adhesion wear. Deep 

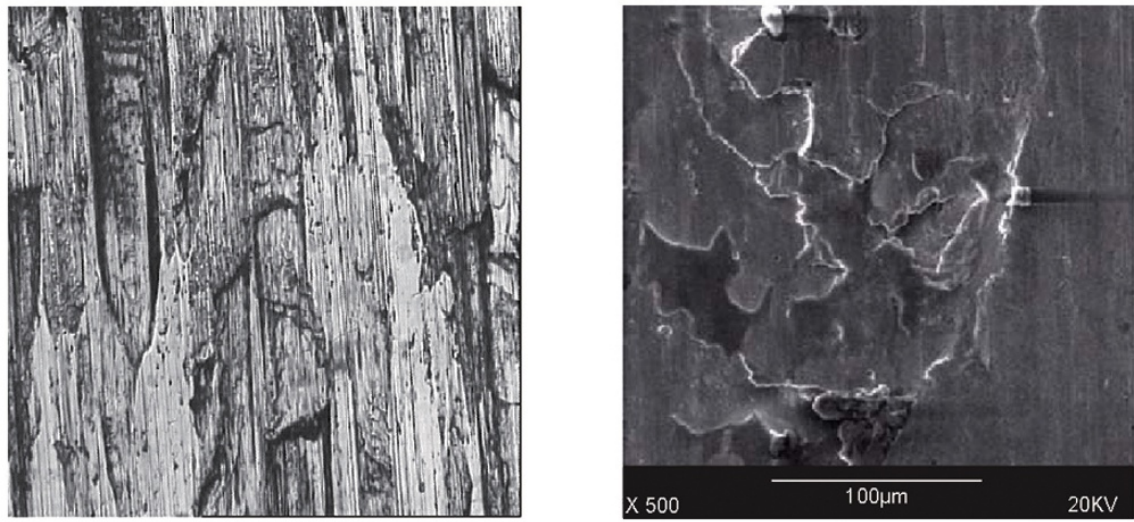

(a) $2500 \mathrm{~N}, 2 \mathrm{~Hz}(\mathrm{OM} \times 100$; SEM $\times 500)$
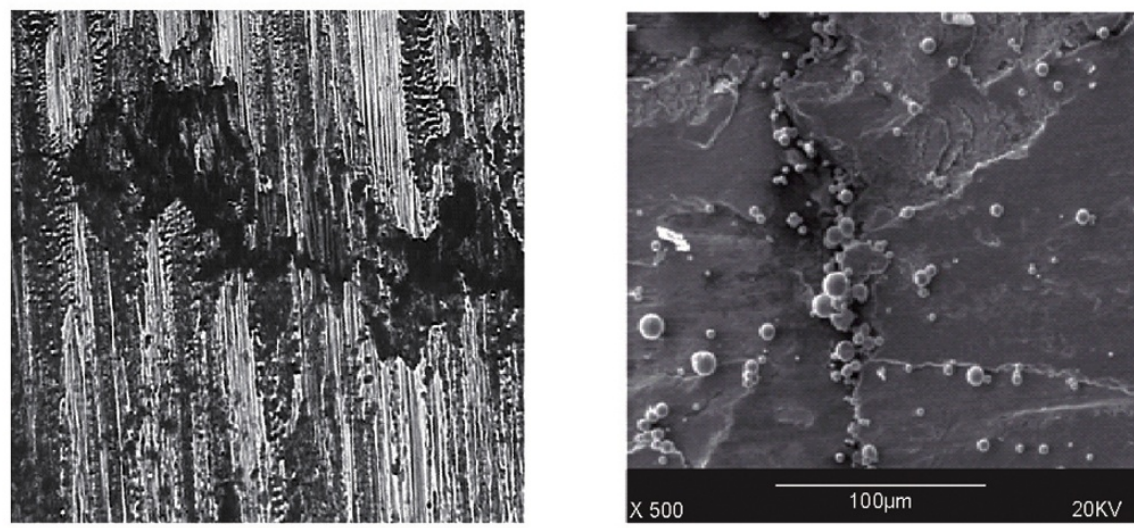

(b) $2500 \mathrm{~N}, 3 \mathrm{~Hz}(\mathrm{OM} \times 100$; SEM $\times 500)$
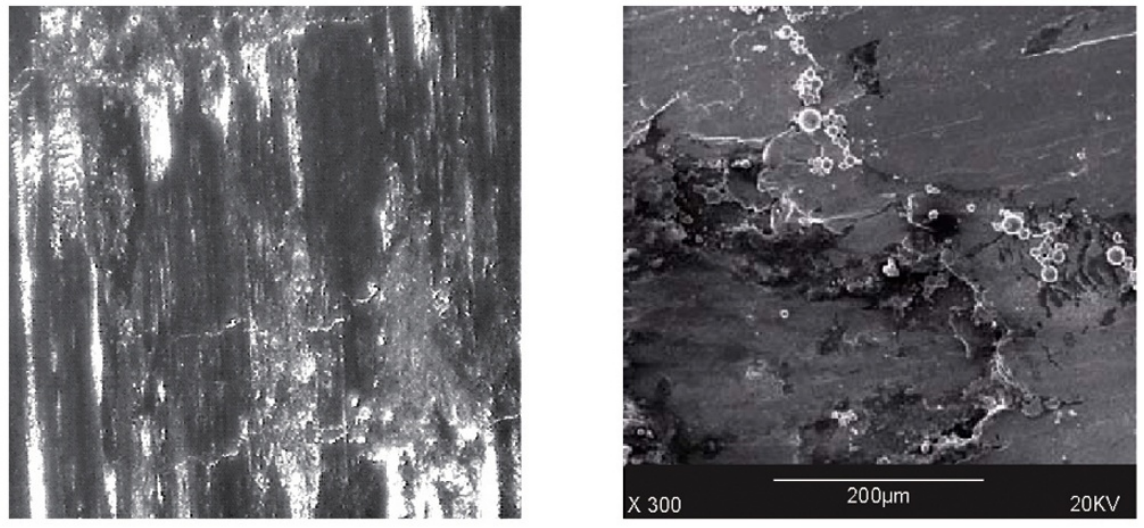

(c) $4000 \mathrm{~N}, 2 \mathrm{~Hz}(\mathrm{OM} \times 100$; SEM $\times 300)$
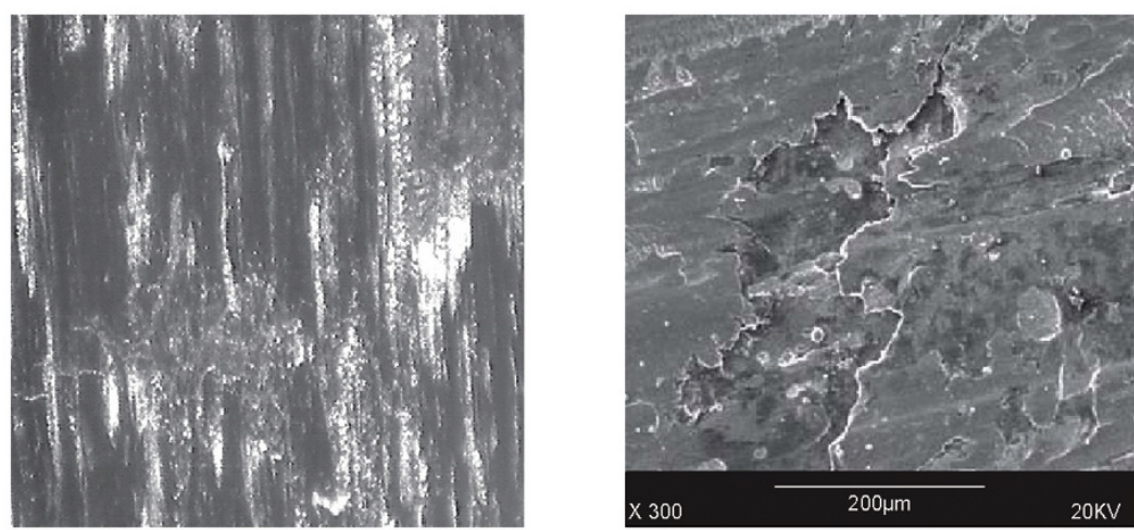

(d) $4000 \mathrm{~N}, 3 \mathrm{~Hz}(\mathrm{OM} \times 100$; $\mathrm{SEM} \times 300)$

Fig. 8 Optical and SEM images of casing surfaces worn under different conditions 
cavities were observed on the SEM image of Fig. 8(c), this is typical of fatigue wear. Connection between fatigue cavities, adhesion wear, and abrasion marks appeared on the SEM image of Fig. 8(d) (Yu et al, 2004).

Under lower impact load conditions, grinding abrasion and contact fatigue are the main mechanisms of casing wear; under higher impact load conditions, adhesion wear and contact fatigue are the main wear mechanisms. The reason for the phenomenon can be described as follows: the temperature of the friction surface rises with increasing impact frequency, plastic flow can be easily produced on the friction surface, more material has been moved and adhesion wear is increasing. On the other hand, the heavy repeated load results in many fatigue cracks generated on the casing surface, these cracks propagate quickly, thus much fatigue wear occurs.

\section{Conclusions}

1) Adhesion wear, contact fatigue, and grinding abrasion are the main wear mechanisms under the impact-sliding test conditions. The friction coefficient and linear wear rate of the casing rise significantly with an increase in impact load.

2) Test results show that the linear wear rate decreases slightly but the average friction coefficient increases slightly with an increase in impact frequency under relative low impact load $(2,500 \mathrm{~N})$. However, both the linear wear rate of the casing and average friction coefficient increase substantially with an increase in impact frequency under relative high impact load $(4,000 \mathrm{~N})$. When the impact frequency is relative low $(2 \mathrm{~Hz})$ the casing wear increases more rapidly at the early stage of wear tests, but when the impact frequency is relative high $(3 \mathrm{~Hz})$ the casing wear increases slowly at the early stage of wear tests and quickly at the later stage.

3) During an impact cycle, relative longer contact time between two samples can cause more casing wear under relative low load $(2,500 \mathrm{~N})$ and impact frequency $(2 \mathrm{~Hz})$. However, under high impact load $(4,000 \mathrm{~N})$ and frequency (more than $2 \mathrm{~Hz}$ ) fatigue micro-cracks form more easily on the surfaces of samples, and the fatigue wear results in more casing wear.

\section{Acknowledgements}

This work was financially supported by the National
Natural Science Foundation of China (No.50475037). The authors are grateful for approval to publish.

\section{References}

Best B. Casing wear caused by tooljoint hardfacing. SPE drilling engineering. 1986. 1(1): 62-70 (SPE paper 11992)

Bol G M. Effect of mud composition on wear and friction of casing and tooljoints. SPE Drilling Engineering. 1986. 1(5): 369-376 (SPE paper 13457)

Bradley W B and Fontenot J E. The prediction and control of casing wear. Journal of Petroleum Technology. 1975. 27(2): 233-243 (SPE paper 5122)

Chen Q, Fan J C, Zhang L B, et al. Development and application of a new type of equipment used in testing surface topography of casing. Lubrication Engineering. 2007. 32(4): 161-162 (in Chinese)

Chu S L. Designs for a New Type Casing Wear Test Machine. MSc Thesis. Beijing: China University of Petroleum. 2006. 74-80 (in Chinese)

Chu S L, Fan J C and Zhang L B. The development of an impactsliding wear test machine. The Ninth International Conference on Engineering Structural Integrity Assessment held in Beijing, October, 2007. 843-846

Chu S L, Zhang L B, Fan J C, et al. Research on calculation model for the impact force of lateral vibration of drilling string in down hole. Drilling and Production Technology. 2008. 31(4): 85-87 (in Chinese)

Fan J C, Zhang L B,Wen D, et al. Combining diagnosis of the casing and tooljoint wear in mud fluid while drilling. Tsinghua Science and Technology. 2004. 9(3): 266-269

Gao B K and Gao D L. Lateral vibration of drill stem in deep wells. Oil Drilling \& Production Technology. 1996. 18(4): 8-14 (in Chinese)

Han C J, Yan T, Bi X L, et al. Rules and their application of drilling string lateral vibration. Daqing Petroleum Institute. 2004. 28(1): 1416 (in Chinese)

Mitchell R F and Allen M B. Lateral vibration: the key to BHA failure analysis. World Oil. 1985. (3): 101-106

Yu L, Zhang L B and Fan J C. Influence of iron ore powder and barite on the friction and wear behavior of casing and drill pipe pair. Tribology. 2004. 24(5): 462-466 (in Chinese)

Zhang L B, Fan J C and Yu L. Advance of mechanism and prediction technology of casing wear in deep and ultra-deep wells. The 7th National Tribology Conference held in Lanzhou, China, September, 2002. 371-375 (in Chinese)

Zheng X Q and Wang H G. Present state and demand of petroleum China drilling technology. Oil Drilling \& Production Technology. 2003. 25(2): 1-4 (in Chinese) 